\title{
Self-punitive behavior: Effects of number of massed acquisition trials and percentage of goal-shocked extinction trials
}

\author{
MICHAEL D. MATTHEWS \\ Drury College, Springfield, Missouri \\ and \\ HAROLD BABB \\ State University of New York, Binghamton, New York
}

\begin{abstract}
Using a massed trials procedure, rats were given 6,12 , or 24 shock escape acquisition trials in a runway, followed by extinction in which they received no further shock anywhere in the alley, or shock in the goalbox on $0 \%, 10 \%$, or $100 \%$ of extinction trials. Results indicate that number of acquisition trials had no effect on run or start speeds during extinction. Percentage of shocked extinction trials did, however, affect extinction performance measures. In comparison with nonshocked controls, animals shocked on $10 \%$ of trials showed facilitation of extinction response measures. Extinction response measures for animals not shocked or shocked on $100 \%$ of trials were similar. The results further clarify what variables affect goal-shock-induced facilitation of extinction performance, and are discussed in the context of current theoretical interpretations of self-punitive behavior.
\end{abstract}

Historically, the phenomenon of "self-punitive" or "vicious circle" behavior referred to the observation that rats shocked somewhere in the alley of a runway apparatus during the extinction of a shock escape or avoidance response showed facilitation of extinction response measures compared with animals not shocked during extinction (Brown, 1969). The location of the shock was thought to be critical, with facilitation occurring only when the shock was delivered in the alley, and suppression occurring when shock was delivered in the goalbox (Seligman \& Campbell, 1965).

Recently, however, it has been clearly demonstrated that facilitation of extinction response measures can reliably be induced by applying shock in the goalbox during the extinction of shock-motivated escape or avoidance behavior (Anderson, Crowell, \& Brown, 1982; Babb, Kostyla, \& Bennett, 1980; Matthews \& Babb, 1985). The firm establishment of the behavioral reality of this effect is important, because it poses severe problems for theoretical accounts of self-punitive behavior based on the

This research is based on a dissertation submitted (by the first author) to the Psychology Department at the State University of New York at Binghamton, in partial fulfillment of a doctoral degree. Harold Babb served as chair of the doctoral committee. The first author thanks the other members of his committee-Norman Spear, George Deane, and John Casparis-for helpful comments on the manuscript. The project was supported in part by BRSG Grant S07RR07149-09 awarded by the Biomedical Research Support Grant Program, Division of Research Resources, National Institutes of Health.

Requests for reprints should be addressed to Michael D. Matthews, Department of Behavioral Sciences, Drury College, Springfield, MO 65802 . early work using alley shock (Brown, 1969; Melvin, 1971).

The purpose of the current study was to further determine what variables affect the performance of rats given goal-shock during extinction. It is important to identify these variables, because it is already known that variables that may affect the performance of rats shocked in the alley during the extinction of shock escape/avoidance behavior do not necessarily affect such performance in rats when goal-shock is used (Babb, Meeker, \& Matthews, in press). Specifically, the current study examined the effects of number of acquisition trials and percentage of goal-shocked extinction trials on start and run speeds following shock escape training under conditions of massed trials. Earlier research, using a spaced trials procedure and goal-shock on $100 \%$ of extinction trials, indicated that number of acquisition trials does affect extinction performance, with greater facilitation associated with larger numbers of acquisition trials (Babb et al., 1980). Moreover, it has been demonstrated with both spaced and massed trials that percentage of shocked extinction trials affects extinction performance, with higher percentages of goal-shocked trials leading to suppression when a massed trials procedure is used (Meeker, Babb, \& Matthews, 1980) and to facilitation when a spaced trials procedure is used (Matthews \& Babb, 1978). Low percentages of goal-shocked extinction trials lead to facilitation regardless of whether a massed or spaced trials procedure is utilized (Babb et al., 1987).

Thus, the present study examined for the first time the effect of number of massed acquisition trials on extinc- 
tion performance under conditions of goal-shock, and attempted to specify what, if any, interactions might exist between number of acquisition trials and percentage of goal-shocked extinction trials.

\section{METHOD}

\section{Subjects}

The subjects were 54 naive female Long-Evans rats, bred and reared in the laboratory's colony room. They were 100-110 days of age at the time of training and were maintained ad lib on water and standard laboratory rat chow.

\begin{abstract}
Apparatus
The apparatus consisted of a straight runway with an alley $122 \mathrm{~cm}$ long $\times 15.5 \mathrm{~cm}$ wide, a startbox $30 \mathrm{~cm}$ long $\times 15.5 \mathrm{~cm}$ wide, and a goalbox $30 \mathrm{~cm}$ long $\times 26 \mathrm{~cm}$ wide. The runway was $13 \mathrm{~cm}$ high throughout, contained a stainless steel grid floor in the goalbox as well as in the startbox and alley, was covered with clear Plexiglas, and was a medium gray in color except for the grid floor, doors, and ceiling.

The startbox and goalbox were separated from the alley by gate doors, and the goalbox was situated $4 \mathrm{~cm}$ from the end of the alley. Both doors were made of clear Plexiglas and were channeled in aluminum frames that abutted $2 \mathrm{~cm}$ into the alley on both sides. The startbox door contained strips of black plastic tape applied horizontally, each with a length of $5 \mathrm{~cm}$ and a height of $2 \mathrm{~cm}$, and with $0.5 \mathrm{~cm}$ between adjacent strips. The bottom strip was $4 \mathrm{~cm}$ above the grid floor.

Photoelectric beams were situated in the alley, $1 \mathrm{~cm}$ past the startbox door and $1 \mathrm{~cm}$ before the goalbox door, and in the goalbox, $11 \mathrm{~cm}$ past the goalbox door. The grid floor was composed of bars $6.3 \mathrm{~cm}$ wide and spaced $6.3 \mathrm{~cm}$ apart. As measured from the grid, a shock of $1 \mathrm{~mA}$ was delivered through a BRS/LVE shocker-scrambler (Model SGS-003). Latency measures for start and run times were taken by Tektronix TM 503 timers. Other related equipment consisted of Hunter and BRS/LVE timers and relays.

An Edwards Lunger buzzer (Cat. No. 115-2, 24-V ac), the conditioned stimulus (CS), was situated $15 \mathrm{~cm}$ from the end wall of the startbox, resting on soft plastic foam and attached to the apparatus platform with a rubber strip. The buzzer emitted an $83-\mathrm{dB}$ noise, as measured inside the startbox. The ambient noise level in the startbox was $54 \mathrm{~dB}$, which partially reflected the fact that the runway and response measuring clocks were situated inside a sound-insulated room while intermittent noisemaking portions of the apparatus were outside. Noise levels were measured using a General Radio $1551 \mathrm{C}$ sound-level meter using the $20-\mathrm{kHz}$ scale.
\end{abstract}

\section{Procedure}

The experiment was a 3 (number of acquisition trials: 6, 12, or 24) $\times 3$ (percentage of goal-shocked extinction trials: $0 \%, 10 \%$, or $100 \%$ ) $\times 15$ (blocks of 6 trials) design. It consisted of three phases: pretraining, acquisition, and extinction. Pretraining involved $5 \mathrm{~min}$ of handling for 2 days preceding the acquisition phase.

Animals were randomly assigned to one of three groups, which were given 6,12 , or 24 acquisition trials. On each acquisition trial, an animal was placed in the startbox, and $5 \mathrm{sec}$ later the gate door was raised vigorously, and the CS, shock, and a timer came on simultaneously. On exiting the startbox, the rat interrupted the photobeam just inside the alley. This served to stop the start timer and initiate the run timer. The run timer was stopped when the photobeam located at the end of the alley was interrupted. Since shock was not present in the goalbox during acquisition trials, shock terminated as the animal left the alley and entered the goalbox. After entering the goalbox, the rat was allowed to remain there for $30 \mathrm{sec}$, after which time it was removed and replaced in the startbox for the beginning of the next trial. On all trials, the door between the alley and goalbox was lowered when the animal entered the goalbox.

Immediately following acquisition, extinction began. In extinction, rats were given goal punishment on $0 \%, 10 \%$, or $100 \%$ of trials. They encountered no shock in the startbox or alley, but punished animals were administered $0.5 \mathrm{sec}$ of shock in the goalbox $0.2 \mathrm{sec}$ after interrupting the photobeam located inside the goalbox. Nonpunished animals did not encounter shock in any part of the apparatus during extinction trials. For rats punished on $10 \%$ of extinction trials, the sequence of shocked/nonshocked trials was determined randomly within blocks of 10 trials, with the restriction that the first extinction trial was a punished one. Rats were run until an extinction criterion of failure to enter the goalbox within $60 \mathrm{sec}$ after the beginning of a trial was met, or to a maximum of 90 trials. When a rat met the criterion, it was not run on further trials, and it was also assigned a start and run time of $60 \mathrm{sec}$ for its remaining trials. As in acquisition, rats were allowed to remain in the goalbox for $30 \mathrm{sec}$ following each trial, and then were removed to the startbox for the initiation of the next trial. The average intertrial interval (ITI), including goalbox confinement time, was approximately $40 \mathrm{sec}$ for both acquisition and extinction trials.

\section{RESULTS}

Throughout the analyses, start and run latencies were converted to speed scores by taking the reciprocal of the median of each six-trial block and multiplying by 100 . For significance estimates, a rejection region of $p<.05$ was used.

\section{Acquisition}

Figure 1 presents mean run speeds for rats given 6, 12, or 24 acquisition trials. Overall means on this measure for the three groups were 122,142 , and 147 , respectively. These means differed significantly $[F(2,51)=12.81]$. Further analyses indicated that animals given 6 acquisition trials ran slower than those given $12[F(1,51)=$ $14.62]$ or $24[F(1,51)=22.89]$ acquisition trials, and that run speeds of animals given 12 or 24 acquisition trials did not differ significantly $[F(1,51)<1]$. However, inspection of Figure 1 indicates that the escape response was learned quite rapidly by all groups. The mean run speeds for each group on the last trial of acquisition were 139, 144 , and 150 for animals given 6,12 , or 24 acquisition trials, a difference that proved not to be significant $[F(2,51)=1.63]$.

Results of analyses of acquisition start speeds closely mirror results obtained with run speeds. Mean overall start speeds for animals given 6,12 , or 24 acquisition trials were 253,331 , and 416 , respectively $[F(2,51)=15.06]$. Animals given only 6 acquisition trials started slower overall than those given $12[F(1,51)=8.26]$ or 24 $[F(1,51)=6.83]$ trials. As with run speeds; start speeds for the final acquisition trial did not differ among the groups $[F(2,51)<1]$. Start speed means on the last trial for rats given 6,12 , or 24 acquisition trials were 402 , 370 , and 457 , respectively.

\section{Extinction}

A 3 (number of acquisition trials) $\times 3$ (percentage of goal-shocked extinction trials) $\times 15$ (blocks of 6 trials) analysis of variance revealed no significant effect of number of acquisition trials on extinction run speeds $[F(2,45)$ $=1.68$, a significant effect of percentage of shocked extinction trials on extinction runs speeds $[F(2,45)=7.30]$, and no interaction between number of acquisition trials 


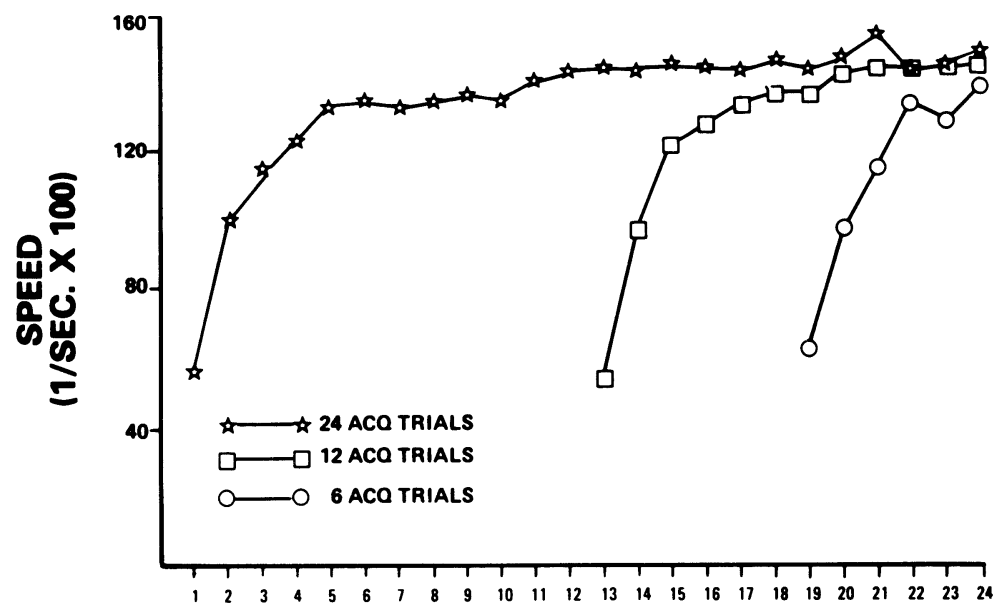

TRIALS

Figure 1. Acquisition run speeds for animals given 6, 12, or 24 acquisition trials.

and percentage of shocked extinction trials $[F(4,45)<1]$. In addition, a significant effects of trial blocks was noted $[F(28,630)=6.55]$. However, neither the trial blocks $X$ number of acquisition trials interaction $[F(28,630)<1]$ nor the triple interaction among trial blocks, number of acquisition trials, and percentage of shocked extinction trials $[F(56,630)=1.15]$ was significant. Consequently, the data were collapsed across number of acquisition trials for subsequent analyses forming three groups: those given $0 \%, 10 \%$, or $100 \%$ shocked extinction trials.

Figure 2 depicts run speed data during extinction for these three groups. Animals given no shock and also those shocked on $100 \%$ of extinction trials show a steady decline in run speeds and do not appear to differ substantially from one another. Subjects shocked on $10 \%$ of extinction trials, in contrast, show a slow but steady increase in run speeds up to the 12th block of extinction, followed by a slight decline over the remaining blocks. Mean run speeds over all 15 blocks for animals shocked on $0 \%, 10 \%$, or $100 \%$ of extinction trials were 87,137 , and 78 , respectively. Statistical analyses indicated a significant effect of percentage of shocked extinction trials $[F(2,51)=7.56]$, a significant effect of trial blocks $[F(14,714)=18.92]$, and a significant interaction between these two factors $[F(28,174)=6.62]$. Comparisons between pairs of means showed that animals shocked on $10 \%$ of extinction trials

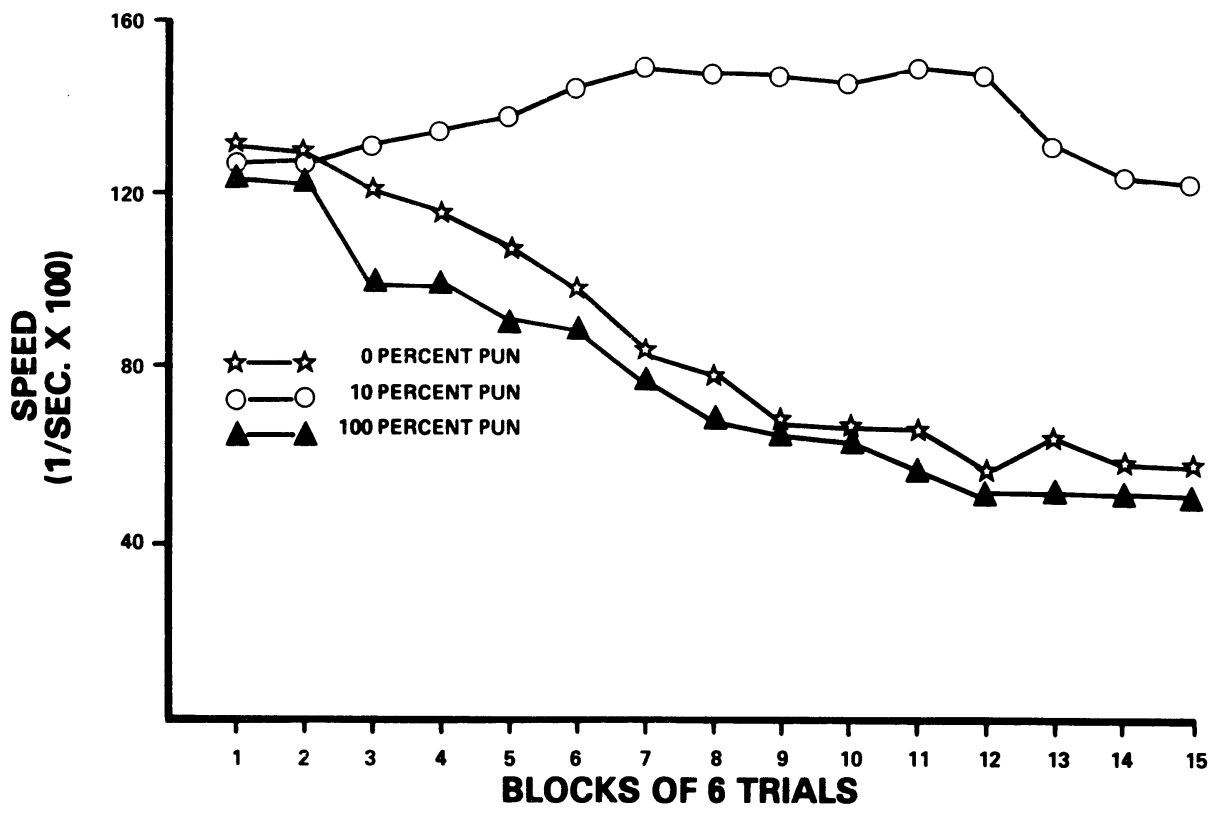

Figure 2. Extinction run speeds for animals administered goal-shock on $0 \%, 10 \%$, or $100 \%$ of extinction trials. 
ran significantly faster than either those not shocked $[F(1,765)=7.01]$ or those shocked on each extinction trial $[F(1,765)=9.98]$. Nonshocked animals and those shocked on each extinction trial did not differ from each other on this measure $[F(1,765) 1]$.

Extinction start speed data were highly similar to extinction run speed data, and for that reason results of analyses based on extinction start speeds are not presented in order to save space. These analyses are available from the first author upon request.

\section{DISCUSSION}

Perhaps the most interesting finding of the study was the failure of number of acquisition trials to have any detectable effect on extinction performance. Any theory based on the concept of fear (e.g., Brown, 1969) would predict some carryover effect from acquisition to extinction, because additional shocked acquisition trials should increase the fear associated with the experimental situation. This finding is not unprecedented. Matthews and Babb (1985) reported that percentage of shocked acquisition trials had no effects on subsequent extinction performance in rats given goal-shock on $0 \%, 10 \%, 50 \%$, or $100 \%$ of extinction trials. In contrast, under conditions of spaced acquisition trials, Babb et al. (1980) did find a significant carryover effect of number of acquisition trials on subsequent extinction performance. It appears that, under conditions of massed trials, acquisition of the initial escape response is rapid, and any possible effects on subsequent extinction are quickly masked. This may not be as true when a spaced trials procedure is used, or when alley shock is used. The latter possibility requires empirical investigation.

An additional contribution of the current study is that it replicated earlier reports that goal-shock may indeed facilitate extinction performance of rats, but only when spaced trials are used or when relatively low percentages of massed trials are used (Babb et al., in press; Matthews \& Babb, 1985). Nevertheless, a complete understanding of what variables influence goal-shock-induced facilitation of extinction response measures remains incomplete. Future inquiry may be profitable in examining the interactions between location of shock, manipulation of acquisition variables, and percentage of shocked extinction trials.
The finding that rats shocked on $100 \%$ of extinction trials performed similarly to those not shocked at all during extinction was unexpected because all previous studies using goal-shock on $100 \%$ of extinction trials reported that such animals rapidly supressed responding compared to nonshocked animals (Babb et al., 1987; Matthews \& Babb, 1985; Meeker et al., 1980). The only procedural difference between this study and previous ones was the use of Long-Evans rats in the current study. Past studies all utilized Sprague-Dawley rats. It is plausible that a strain difference in reactivity to shock may explain the discrepant results.

\section{REFERENCES}

Anderson, D. C., Crowell, C. R., \& Brown, J. S. (1982). Retardation of extinction of an escape response by prolonged, intense goal box shock. Journal of Comparative \& Physiological Psychology, 96. 184-191.

BabB, H., Kostyla, S. J., \& Bennett, W. (1980). Escape conditioning and goal punishment: Effects of acquisition trials, initial punishment trials, and CS extent. Learning \& Motivation, 11, 386-406.

BabB, H., Meeker, D. J., \& MatTHews, M. D. (in press). Goal punishment versus alley punishment: Contrasting effects from trial spacing and punishment frequency. Animal Learning \& Behavior.

Brown, J. S. (1969). Factors affecting self-punitive locomotor behavior. In B. A. Campbell \& R. M. Church (Eds.), Punishment and aversive behavior. New York: Appleton-Century-Crofts.

MatThEWs, M. D., \& BABB, H. (1978). Effects of percentage of goalpunished extinction trials on self-punitive behavior. Bulletin of the Psychonomic Society, 12, 64-66.

MatTHEws, M. D., \& BABB, H. (1985). Self-punitive behavior: Effects of percentage of shocked acquisition trials and percentage of goalshocked extinction trials. The Psychological Record, 35, 535-547.

MeEker, D. J., BABB, H., \& MatThews, M. D. (1980). Goal vs. alley punishment after escape training: Massed trials and startbox conditions. Bulletin of the Psychonomic Society, 16, 51-54.

MeLVIN, K. B. (1971). Vicious circle behavior. In H. D. Kimmel (Ed.), Experimental psychopathology: Recent research and theory. New York: Academic Press.

Seligman, M. E. P., \& CAmpbell, B. A. (1965). Effects of duration and intensity of punishment on extinction of an avoidance response. Journal of Comparative \& Physiological Psychology, 59, 295-297.

(Manuscript received for publication April 8, 1987.) 